\section{Effective Pollination Period in Almond Cultivars}

\author{
E. Ortega, J. Egea, and F. Dicenta ${ }^{1}$ \\ Departamento de Mejora y Patología Vegetal, CEBAS-CSIC, P.O. Box 4195, \\ 30080 Murcia, Spain
}

Additional index words. Prunus dulcis, cross-pollination, stigma receptivity, fluorescence microscopy, fruit set, temperature effect

\begin{abstract}
In almond [Prunus dulcis (Mill.) D.A. Webb], a high flower density and fruit set rate is important, because yield increases with higher fruit set ratio. Furthermore, because the ovule of some cultivars mature at anthesis, rapid pollination and pollen tube growth along the style are essential to ensure fertilization of a viable ovule. In this work, we studied the effective pollination period (EPP) of four almond cultivars of different bloom time by studying pollen tube growth and fruit set. EPP in almond was longer than in other fruit trees, and its duration was determined by stigma receptivity, which decreased with high temperature. An acceptable fruit set for all cultivars was obtained following pollination from day 0 to day 4 after emasculation.
\end{abstract}

Successful pollination in fruit trees is essential to obtain a good yield. In almond, the more flowers that are pollinated, the greater the number of fruits (Kester and Griggs, 1959), and even if fruit size is somewhat smaller, the total yield will be higher (Hill et al., 1987). Therefore, a high density of flowers and a high fruit set are of great interest for almond growers.

Effective pollination period (EPP) was first described in apple, as ovule longevity minus the time between pollination and fertilization (Williams, 1965). This period of time is determined by several genetic, physiological and environmental conditions occurring during flowering. Among the environmental factors, high temperature can shorten the EPP by affecting stigma receptivity, pollen tube growth or ovule viability in different species (Burgos et al., 1991; González et al., 1995; Tonutti et al., 1991; Tromp and Borsboom, 1994; Williams, 1966).

The EPP has been studied in different fruit tree species, such as apple, pear, sweet cherry, sour cherry, peach, apricot, kiwifruit, and plum (Burgos et al., 1991; Cerović et al., 2000; Egea and Burgos, 1992; Furukawa and Bukovac, 1989; González et al., 1995; Stösser and Anvari, 1983; Tonutti et al., 1991; Toyama, 1980; Tromp and Borsboom, 1994; Williams, 1966).

In almond, the importance of the length of the period of flower receptivity in obtaining a good yield was first described by Griggs and Iwakiri (1964). In this study, fruit set of the almond cultivar 'Nonpareil' following con-

Received for publication 5 Aug. 2002. Accepted for publication 26 Mar. 2003. We thank Mariano Gambín, Adela Martínez and José Luís Patiño for technical assistance in the experiments presented in this paper. The work has been financed with the project "Mejora Genética delAlmendro" (AGL20011054-C03-01) from the "Plan Nacional de I+D" of Spanish Ministry of Science and Technology

${ }^{1}$ To whom reprint requests should be addressed. E-mail address: fdicenta@cebas.csic.es trolled pollination with a compatible cultivar at different times after emasculation was determined. The results indicated that almond flowers are most receptive for a day or two after anthesis and remain receptive for 3 or 4 d. In a later study (Griggs and Iwakiri, 1975) the results showed that, even under favorable weather conditions, pollen tube growth along the style of almond flowers of 'Nonpareil' and 'Texas' takes 4-5 d.

Other almond studies reported that pollen tubes required from $2-4 \mathrm{~d}$ more to reach the ovule (Pimienta et al., 1983; Polito et al., 1996). This time lag has been explained by the immaturity of the embryo sac, which fully develops after pollen tubes reach the ovary (Pimienta and Polito, 1983). However, Egea and Burgos (2000) observed a great variability between almond cultivars regarding stage of maturity of ovules at anthesis and $3 \mathrm{~d}$ later. So, in those almond cultivars with mature ovules at anthesis, an early pollination and quick pollen tube growth are essential to reach a viable ovule. Nyomora et al. (2000) suggested that foliar boron application in almond increases pollen tube growth rate and extend EPP.

The objective of this work was to determine the EPP in four almond cultivars flowering under different temperature regimes.

\section{Materials and Methods}

For this study three almond cultivars, 'Ramillete', 'Marcona', and 'Marta', and 'S5133' [a selection from Centro de Edafología y Biología Aplicada del Segura (CEBAS)], with a blooming time of $33,40,47$, and 68 Julian days, respectively, were cross-pollinated by hand with pollen of compatible cultivars having a similar blooming period ('Desmayo Largueta', 'DelCid', 'Marcona', and 'A2198', respectively).

Pollen was obtained by desiccation of anthers from flowers at stage ' $D$ ' (Felipe, 1977) for $48 \mathrm{~h}$ at room temperature and then placed in small glass bottles and stored at $4{ }^{\circ} \mathrm{C}$ until pollination. Fresh pollen was used each day.
The in vitro germination of the pollen was tested in petri dishes, on a $15 \%$ sucrose plus $1.2 \%$ agar medium (Remy, 1953).

For each cultivar, flower buds at stage ' $\mathrm{D}$ ' (Felipe, 1977) were emasculated and crosspollinated by hand using a paintbrush at 0,2 , 4 , and $6 \mathrm{~d}$ after emasculation.

A sample of 30 pistils for each cultivar and each time was collected $96 \mathrm{~h}$ after pollination and fixed in FAA [a fixing solution consisting of $40 \%(\mathrm{v} / \mathrm{v})$ formaldehyde, glacial acetic acid and $70 \%$ ethanol at a ratio of $1: 1: 18]$. In preparation for microscopy, the pistils were washed several times and autoclaved for 30 min at a pressure of $1 \mathrm{~kg} \cdot \mathrm{cm}^{-2}$, in a solution of $5 \%$ sodium sulphite, to soften the tissue and to enhance staining. The stain used was $0.1 \%$ aniline blue in $0.1 \mathrm{~N}$ potassium phosphate. Before squashing the pistils the pubescence was removed.

The number of pollen tubes in the upper part of each style was determined by means of fluorescence microscopy (Kho and Baër, 1968; Linskens and Esser, 1957; Martin, 1959). A total of 480 pistils were observed.

Fruit set of each cultivar at different days after pollination was also determined. For this, flower buds were emasculated and pollinated by hand at $0,2,4$, and $6 \mathrm{~d}$ after emasculation and fruits counted 30 and $60 \mathrm{~d}$ after pollination. The initial and final fruit sets, after physiological drop (June drop) took place, were calculated as the percentage of pollinated flowers becoming fruits. Three branches (containing 80 flowers each on average) were studied per cultivar and time of pollination; thus, 48 branches were studied in total.

Climatic data for February and March were recorded in a meteorological station located in the experimental field. The mean temperatures during the $6 \mathrm{~d}$ of the assay for each cultivar are shown (Fig. 1). The mean temperature of this period was $13.8^{\circ} \mathrm{C}$ for 'Ramillete', $14.4^{\circ} \mathrm{C}$ for 'Marcona', $12.4^{\circ} \mathrm{C}$ for 'Marta', and $19.1^{\circ} \mathrm{C}$ for 'S5133'. Each day (1 to 6) for each cultivar corresponded to different calendar. The later the flowering of the cultivar, the higher the mean daily temperature. Furthermore, in the case of 'S5133' the temperatures were above those expected on those dates. The lower temperatures at flowering in the case of 'Marta' were due to rainy weather.

Data for pollen tubes in the style and fruit set were analyzed by the General Linear Model procedure of SAS software (SAS Institute, 1989) to determine the differences between cultivars and treatments. Fruit set percentages were previously transformed by calculating the arcsine value of the square root and mean values were analyzed by Duncan's multiple range test.

\section{Results}

A general decrease in the percentage of stigmas with pollen from day 0 to day 6 for the different cultivars was observed (Fig. 2). Those stigmas without pollen were no longer receptive when pollinated, and then pollen grains did not germinate and were removed during the staining process. This effect in- 
creased according to the blooming time of the cultivars, from the earliest ('Ramillete') to the latest ('S5133'). The loss of receptivity was caused by stigma desiccation with increasing temperatures during the 6-d period. However, in the case of 'Marta', the lowest number of stigmas with pollen corresponded to day 2 after emasculation. This was presumably caused by the washing effect of the rain in the few hours after pollination.

For the number of pollen tubes in the style, analysis of variance (ANOVA) showed significant differences between cultivars and times, their interaction also being significant (Table 1).

For most of the cultivars, the highest number of pollen tubes in the upper part of the style corresponded to days 0 and 2, and the lowest number at day 6 (Fig. 3). However, 'Marta' showed the highest number of pollen tubes at day 6 . This was probably due to the cool mean temperature $\left(12.4{ }^{\circ} \mathrm{C}\right)$, together with high relative humidity, from days 0 to 6 of the flowering of 'Marta', which allowed stigma to be receptive longer.

Regarding fruit set at 30 and 60 d, ANOVA

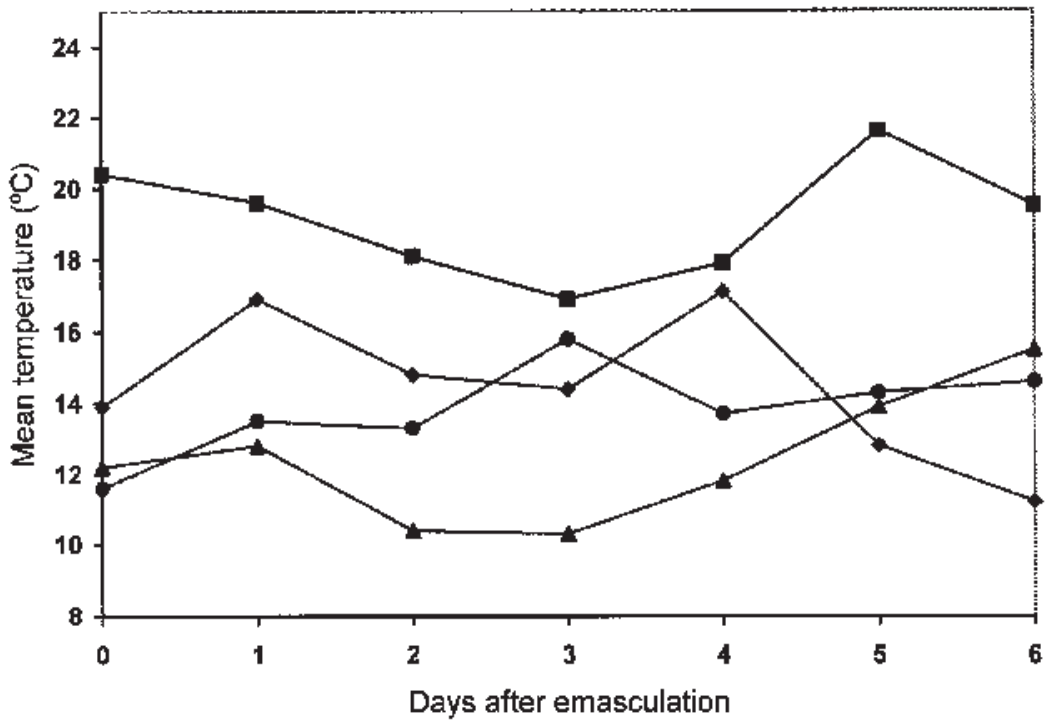

$\rightarrow-$ Ramillete $\rightarrow-$ Marcona $-4-$ Marta $\rightarrow-55133$

Fig. 1. Mean temperature for each day after emasculation, for each cultivar.

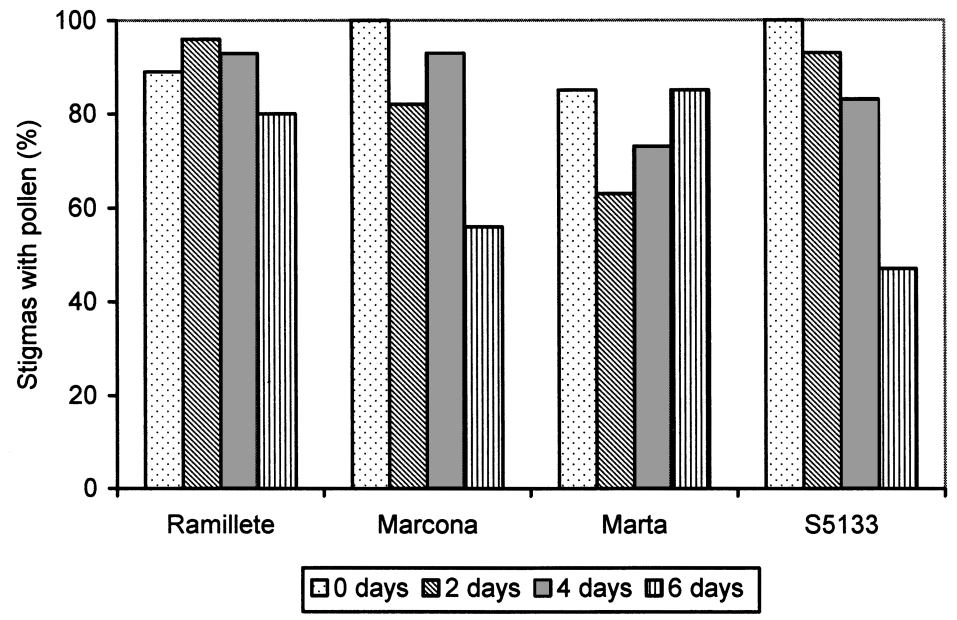

Fig. 2. Percentage of stigmas with pollen for each cultivar and for each time after emasculation.

Table 1. Analysis of variance for the number of pollen tubes in the upper part of the style, fruit set $30 \mathrm{~d}$ after pollination and fruit set after $60 \mathrm{~d}$.

\begin{tabular}{|c|c|c|c|c|c|c|c|c|c|}
\hline & \multicolumn{3}{|c|}{ Pollen tubes in the style } & \multicolumn{3}{|c|}{ Fruit set at $30 \mathrm{~d}$} & \multicolumn{3}{|c|}{ Fruit set at $60 \mathrm{~d}$} \\
\hline & $\mathrm{df}$ & MS & $\mathrm{F}$ & df & MS & $\mathrm{F}$ & $\overline{\mathrm{df}}$ & MS & $\mathrm{F}$ \\
\hline$\overline{\text { Cultivar (C) }}$ & 3 & 2523.95 & $20.50^{y}$ & 3 & 0.39 & $26.04^{y}$ & 3 & 0.05 & $4.21^{2}$ \\
\hline Time $(\mathrm{T})$ & 3 & 2812.75 & $22.84^{y}$ & 3 & 0.10 & $6.96^{z}$ & 3 & 0.04 & $3.57^{2}$ \\
\hline $\mathrm{C} \times \mathrm{T}$ & 9 & 1752.58 & $14.23^{\mathrm{y}}$ & 9 & 0.13 & $8.64^{y}$ & 9 & 0.10 & $8.31^{y}$ \\
\hline Error & 439 & 123.13 & & 32 & 0.01 & & 32 & 0.01 & \\
\hline
\end{tabular}

${ }^{\mathrm{z}} P<0.05$.

${ }^{\mathrm{y}} P<0.01$.

Abbreviations: $\mathrm{df}=$ degrees of freedom; $\mathrm{MS}=$ mean square; $\mathrm{F}=\mathrm{F}$ value. showed significant differences between cultivars and times, their interaction also being significant (Table 1). Fruit set recorded at $30 \mathrm{~d}$ was obviously higher than fruit set at 60 d (Figs. 4 and 5).'

'Marcona' did not show differences for fruit set at $30 \mathrm{~d}$ between pollination treatments. ' $\mathrm{Ra}$ millete' showed a lower fruit set at day 6 , which was similar to results obtained in Marcona. This results indicate that the EPP, in our conditions, extended until day 6 in both cultivars, which flowered during an intermediate temperature period. The results of fruit set obtained at 60 d (Fig. 5) show a similar tendency for both cultivars, but values were lower because of physiological fruit drop.

Pollination at day 2 of 'Marta' differed from the other cultivars (Fig. 4), due to the lower fruit set obtained at $30 \mathrm{~d}$, probably a consequence of the rain after pollination. The other pollination treatments reached similar values, which indicate that a temperature regime below the expected extended the EPP, as the fruit set on day 6 was higher than in the other cultivars. For fruit set at $60 \mathrm{~d}$, the results were similar, and fruit drop was lower than in the case of 'Ramillete' (Fig. 5).

Finally, fruit set for 'S5133', the latest flowering cultivar, decreased considerably from days 0 to 6 . This was probably due to the negative influence of the higher temperature regime during the 6- $\mathrm{d}$ period shortening the EPP by 1 or $2 \mathrm{~d}$. Again, fruit set at $60 \mathrm{~d}$ had a similar pattern but with lower values (Fig. 5).

\section{Discussion}

The study of pollen tubes in the upper part of the style revealed that stigma receptivity decreased with time from flower opening. This effect was more important when temperatures at flowering were higher, as shown in the case of 'S5133' which has a later blooming period.

Except for 'S5133', fruit set was acceptable, even at day 6 , for all cultivars, with no great decrease from day 0 values being shown. This was in contrast with the results obtained with the cultivar 'Nonpareil' by Griggs and Iwakiri (1964), who observed that at five or more days after anthesis, fruit set was almost nil.

Except for 'Marcona', the important decrease of pollen tubes in the style at day 6 promoted a decrease in fruit set. Nevertheless, differences between times of pollination, regarding the number of pollen tubes for each cultivar, were not so evident for fruit set at 30 $\mathrm{d}$ and even less so for fruit set at $60 \mathrm{~d}$. This means that a low number of pollen tubes could be enough to ensure fruit set.

The lower fruit set at day 6 for 'S5133' could be a consequence of the low number of pollen tubes in the style. But, as 'Marcona', with the same mean number of pollen tubes in the style, showed an acceptable fruit set on that day, the explanation could rather be an early ovule degradation because of higher temperatures, particularly after day 4, in 'S5133'.

Loss of ovule viability due to high temperatures at flowering was suggested by Cerović et al. (2000) in plum. An important fall was 


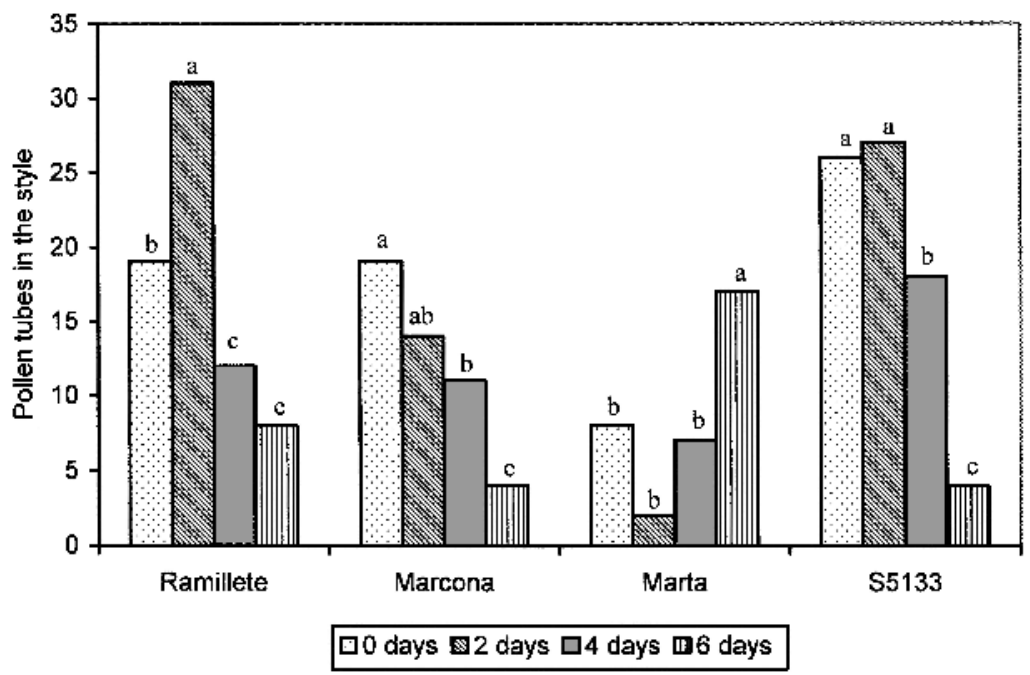

Fig. 3. Mean number of pollen tubes in the upper part of the style for each cultivar and for each time after emasculation. Different letters for the same cultivar indicate significant differences, according to Duncan's multiple range test $(P=0.05)$.

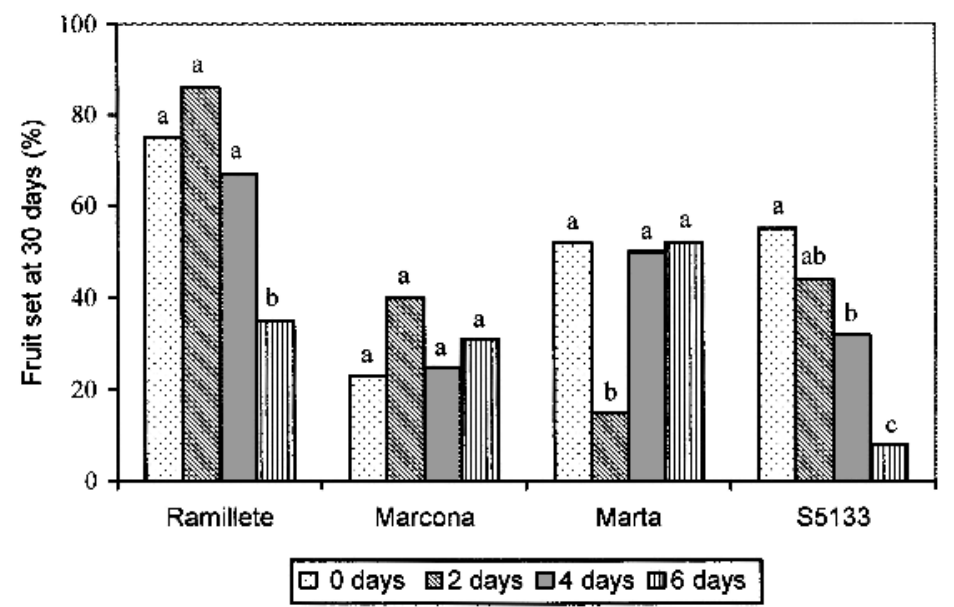

Fig. 4. Mean fruit set (\%) $30 \mathrm{~d}$ after pollination for each cultivar and for each time. Different letters for the same cultivar indicate significant differences, according to Duncan's multiple range test $(P=0.05)$.

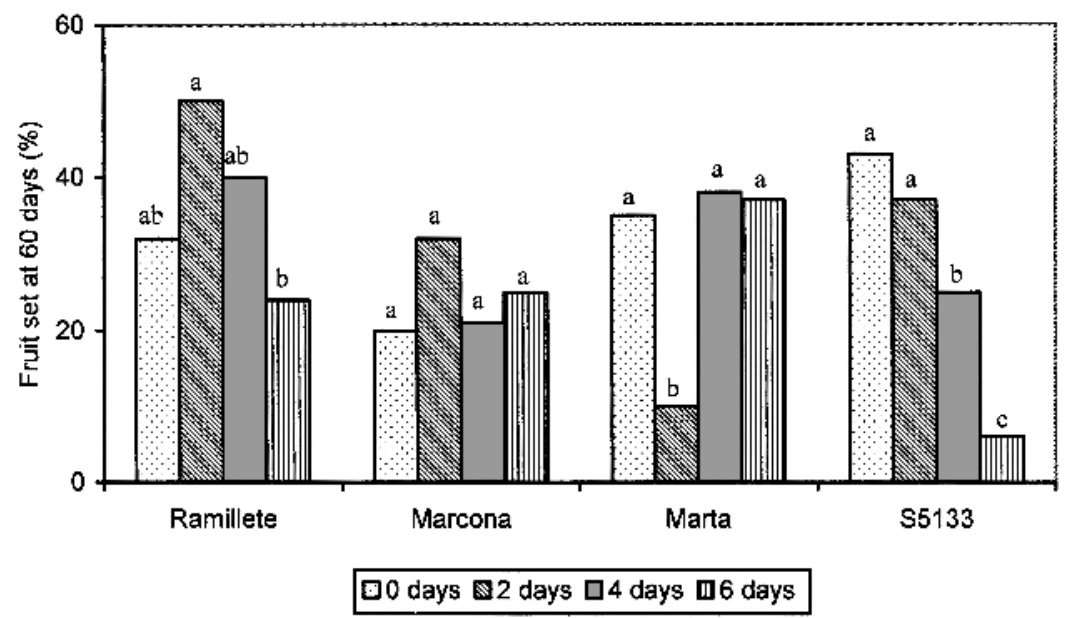

Fig. 5. Fruit set (\%) $60 \mathrm{~d}$ after emasculation for each cultivar and for each time. Different letters for the same cultivar indicate significant differences, according to Duncan's multiple range test $(P=0.05)$. observed for the number of viable ovules at $20{ }^{\circ} \mathrm{C}$. However, ovules remained viable during the full period at lower temperatures $(5,10$ and $\left.15{ }^{\circ} \mathrm{C}\right)$. Adifferent response to temperature was observed between cultivars.

The negative effect of high temperatures on ovule degradation was also observed under laboratory conditions in pear and apple cultivars by Williams (1970). Nevertheless, under field conditions EPP was shortened by low temperature, because of the slower pollen tube growth.

Burgos et al. (1991) and Egea and Burgos (1992) observed a rapid stigma degradation under higher temperatures in apricot, with a subsequent shorterEPP. When the temperature regime was lower the EPP was longer, as was the case with our earlier-flowering cultivars.

A longer EPP under lower temperatures was also observed in pear by Vasilakakis and Porlingis (1985), and later by Tromp and Borsboom (1994) for apple and pear cultivars. Likewise, in kiwifruit, high temperatures were responsible for the loss of stigma receptiveness, shortening EPP (González et al., 1995).

Our results revealed a different behavior of the studied cultivars, mainly influenced by the different temperatures at flowering. But, with the exception of 'S5133', results were also different under similar mean temperatures. Nevertheless, fruit set values for all cultivars, for the period studied ( $0-6 \mathrm{~d})$, indicate that in almond EPP is longer than in other species such as apricot (Egea and Burgos, 1992).

Low productivity (linked to a low fruit set) of some almond cultivars of extra-late blooming period (Grasselly, 1977, 1978; Kester, 1965) could be related to an important shortening of the EPP, because these cultivars usually flower under higher temperatures. In our conditions, this effect was observed only in the case of 'S5133' when pollinated at day 6.

Nevertheless, because the pistil in almond is receptive at anthesis (Egea and Burgos, 2000), an acceptable fruit set would be possible on the first days after flower opening. In fact, 'S5133' is a highly productive selection. This was also observed in kiwifruit, where, because of pistil maturity at anthesis, high fruit set was achieved from the first day after pollination (González et al., 1995).

We conclude that the long EPP of almond allows an acceptable fruit set, even under a high temperature regime for a late blooming period cultivar.

\section{Literature Cited}

Burgos, L., J. Egea, and F. Dicenta. 1991. Effective pollination period in some apricot cultivars. Ann. Appl. Biol. 119:533-539.

Cerović, R., Đ. Ružić, and N. Mićić. 2000. Viability of plum ovules at different temperatures. Ann. Appl. Biol. 137:53-59.

Egea, J. and L. Burgos. 1992. Effective pollination period as related to stigma receptivity in apricot. Scientia Hort. 52:77-83.0

Egea, J. and L. Burgos. 2000. Ovule differences between single-kernelled and double-kernelled fruits in almond (Prunus dulcis) Ann. Appl. Biol. 73:107-110.

Felipe, A. 1977. Stadi fenologici del mandorlo. p 
101-103. Proc. 3rd GREMPA Colloq. 3-7 Oct. 1977, Valenzano, Bari, Italy. Edizioni Quadrifoglio, Bari.

Furukawa,Y. and M.J. Bukovac. 1989. Embryo sac development in sour cherry during the pollination period as related to fruit set. HortScience 24:1005-1008.

González, M.V., M. Coque, and M. Herrero. 1995. Stigmatic receptivity limits the effective pollination period in kiwifruit. J. Amer. Soc. Hort. Sci. 120:199-202.

Grasselly, C. 1977. Qué peut-on attendre de l'amélioration génétique de l'amandier? La Pomologie Française 19:77-84.

Grasselly, C. 1978. Observations sur l'utilisation d'un mutant d'amandier à floraison tardive dans un programme d'hybridation. Annales de l'Amélioration des Plantes 28:695.

Griggs, W.H. and B.T. Iwakiri. 1964. Timing is critical for effective cross pollination of almond flowers. Calif. Agr. Jan.:6-7

Griggs, W.H. and B.T. Iwakiri. 1975. Pollen tube growth in almond flowers. Calif. Agr. July: 4-.

Hill, S.J., D.W. Stephenson, and B.K. Taylor. 1987. Almond yield in relation to tree size. Scientia Hort. 33:97-111.

Kester, D.E. 1965. Inheritance of time of bloom in certain progenies of almond. Proc. Amer. Soc. Hort. Sci. 87:214-221.

Kester, D.E. and W.H. Griggs. 1959. Fruit set in almond: The effect of cross-pollinating various percentages of flowers. Proc. Amer. Soc. Hort. Sci. 74:206-213.

Kho, Y.O. and J. Baër. 1968. Observing pollen tubes by means of fluorescence. Euphytica 17: 298-302.

Linskens, H.F. and K. Esser. 1957. Über eine spezifische anfärbung der pollenschläuche im griffel und die zahl der kallosepfropfen nach selbstung und fremdung. Naturwissenschaften 44:16.

Martin, F.W. 1959. Staining and observing pollen tubes in the style by means of fluorescence. Stain Technol. 34:125-128.

Nyomora, A.M.S., P.H. Brown, K. Pinney, and V.S. Polito. 2000. Foliar application of boron to almond trees affects pollen quality. J. Amer. Soc. Hort. Sci. 125:265-270.

Pimienta, E. and V.S. Polito. 1983. Embryo sac development in almond [Prunus dulcis (Mill.) D.A. Webb] as affected by cross-, self-, and nonpollination. Ann. Bot. 51:469-479.

Pimienta, E., V.S. Polito, and D.E. Kester. 1983. Pollen tube growth in cross- and self-pollinated 'Nonpareil' almond. J.Amer. Soc. Hort. Sci. 108: 643-647.

Polito, V.S., W.C. Micke, and D.E. Kester. 1996. Bud development, pollination and fertilization, p. 98-102. In: W.C. Micke (ed.). Almond production manual. Div. Agr. and Natural Resources, Univ. of California.

Remy, P. 1953. Contribution a l'etude du pollen des arbres fruitiers a noyau, genere Prunus. Annales de l'Amélioration des Plantes 3:351-388.
SAS Institute (1989) SAS/STAT user's guide. SAS Inst., Cary, N.C.

Stösser, R. and S.F. Anvari. 1983. Pollen tube growth and fruit set as influenced by senescence of stigma, style and ovules. Acta Hort. 139:13-22.

Tonutti, P., A. Ramina, F. Cossio, and G. Bargioni. 1991. Effective pollination period and ovule longevity in Prunus avium L. Adv. Hort. Sci. 5:157-162

Toyama, T.K. 1980. The pollen receptivity period and its relation to fruit setting in the stone fruits. Fruit Var. J. 34:2-4.

Tromp, J. and O. Borsboom. 1994. The effect of autumn and spring temperature on fruit set and on the effective pollination period in apple and pear. Scientia Hort. 60:23-30.

Vasilakakis, M. and I.C. Porlingis. 1985. Effect of temperature on pollen germination, pollen tube growth, effective pollination period, and fruit set of pear. HortScience 20:733-735.

Williams, R.R. 1965. The effect of summer nitrogen on the quality of apple blossom. J. Hort. Sci. 40:31-41.

Williams, R.R. 1966. Pollination studies in fruit trees: III. The effective pollination period for some apple and pear varieties Rpt. of Long Ashton Res. Sta. for 1965:136-138.

Williams, R.R. 1970. Factors affecting pollination in fruit trees, p. 193-207. In: L.C. Luckwill and C.V. Cutting (eds.). Physiology of tree crops. Academic, London and New York. 